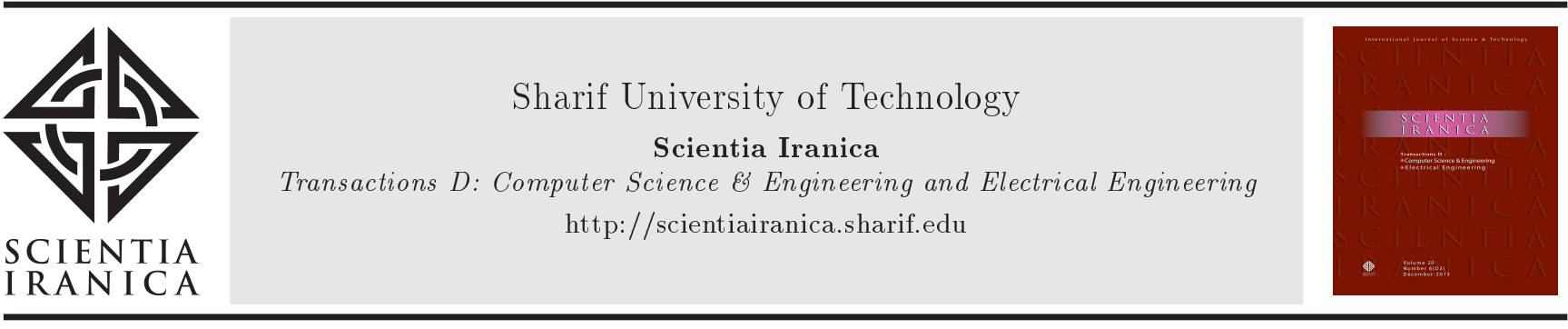

\title{
Cogging torque reduction of Interior Permanent Magnet Synchronous Motor (IPMSM)
}

\author{
M. Arehpanahi* and H. Kashefi \\ Department of Electrical Engineering, Tafresh University, Tafresh, P.O. Box 39518 79611, Iran.
}

Received 23 December 2014; received in revised form 20 June 2016; accepted 26 September 2016

\begin{abstract}
KEYWORDS
Cogging torque; Segmented PM; Pole-arc ratio;

Saturation and response surface method.
\end{abstract}

\begin{abstract}
In this paper, the torque ripple of Interior Permanent-Magnet Synchronous Motor (IPMSM) is reduced using combination of two separate ideas. These two ideas are segmented PM rotor and modified the rotor structure based on pole-arc ratio of flux barrier optimization. In addition, the torque ripple is decreased due to the reluctance torque component reduction. Analysis and simulation results, including saturation, were performed using analytical method and Finite-Element Method (FEM). The configuration of rotor flux barrier of the proposed design was carried out by Response Surface Method (RSM) as an optimization technique, verified by FEM.

(C) 2018 Sharif University of Technology. All rights reserved.
\end{abstract}

\section{Introduction}

Magnetic interaction between stator tooth and rotor magnets in IPMSM produces output torque fluctuation called cogging torque. Cogging torque makes a noise and vibration in the motor speed. There are several methods for the reduction of cogging torque such as segmented permanent magnet [1], flux barrier employed in rotor structure [2], the continuum sensitive analysis combined with the FEM for rotor structure design [3], and optimization of shape and position of notches in the rotor structure [4]. A modified V-type magnet angle and rotor surface shape as a new design of IPM motor for electric air-conditioning system of Hybrid Electric Vehicle (HEV) are proposed in [5]. Some of these techniques are not practical and are expensive. In this paper, using combination of two separate ideas, i.e. segmented PM and pole-arc ratio optimization of the flux barriers, a new design is investigated.

\footnotetext{
*. Corresponding author.

E-mail address: arehpanahi@tafreshu.ac.ir (M. Arehpanahi)
}

doi: $10.24200 /$ sci. 2017.4365
Generally, the cogging torque equation is computed by Eq. (1) [6]:

$$
T_{c}(\theta)=\frac{l \pi}{4 \mu_{0}}\left(R_{1}{ }^{2}-R_{2}{ }^{2}\right) \sum_{n=1}^{\infty} n N_{c} G_{a n} B_{a n} \sin n N_{c} \theta,
$$

where $l, \mu_{0}, R_{1}, R_{2}, n, N_{c}, G_{a n}, B_{a n}$, and $\theta$ are rotor length, air permeability, inner and outer rotor radii, harmonic order, least common multiplier between rotor poles and stator slots, Fourier coefficient of air gap permeance, flux density, and mechanical angle, respectively.

Based on IPMSM structure, permanent magnets are inside the rotor body, and iron bridges surrounding the PMs are always in saturation; therefore, this magnetic nonlinearity for accurate analysis of motor behavior must be considered [6]. To obtain the general and optimized design, at first, the initial design is considered. Then, the two separate ideas are applied to the initial design step by step.

\section{Calculation of $L_{q}$ and $L_{d}$}

The computation of $L_{d}$ and $L_{q}$ ( $d$ and $q$ inductances) affected motor performance analysis and design di- 
rectly. In addition, in IPMSM, $L_{d}$ is in saturation region because the PM flux is crossing through $d$ axis direction; therefore, the value of $L_{d}$ varies with the stator current. Then, the accuracy of inductance calculation method in nonlinear condition (saturation effect) is very important. In this paper, using [7], these inductances are calculated as expressed in Eq. (2):

$$
\begin{aligned}
& \lambda_{d_{-} \text {total }}=\lambda_{d_{-} P M}+L_{d} i_{d} \Rightarrow L_{d}=\frac{\lambda_{d_{-} \text {total }}-\lambda_{d_{-} P M}}{i_{d}}, \\
& L_{q}=\frac{\lambda_{q}}{i_{q}}
\end{aligned}
$$

where $\lambda_{d_{\text {total }}}$ and $\lambda_{d_{-} P M}$ are total flux linkage and $P M$ flux linkage of $d$ axis, respectively. Therefore, by considering the saturation, the flux linkage due to the stator winding and $P M\left(\lambda_{d_{-} \text {total }}\right)$ and flux linkage due to the $P M$ alone $\left(\lambda_{d_{-} P M}\right)$ are computed separately. Then, both inductances are obtained using Eq. (2).

\section{Cogging torque reduction of IPMSM}

\subsection{Modifying the rotor structure}

The initial design was selected from [8]. Magnetic characteristics of a $9 \mathrm{~kW}$, 4-pole, $120 \mathrm{~V}$ IPMSM (stator and rotor materials) is illustrated in Figure 1, and motor specification is listed in the appendix. This IPMSM is used for traction applications.

In the first step, the rotor structure with three limitations defined below is optimized using genetic algorithm as optimization tools:

1. Air gap limitation: $0.6 \mathrm{~mm} \leq g \leq 1.2 \mathrm{~mm}$;

2. $P M$ thickness limitation: $8.8 \mathrm{~mm} \leq W_{m} \leq 9.6 \mathrm{~mm}$;

3. $P M$ width limitation: $87 \mathrm{~mm} \leq l_{m} \leq 95 \mathrm{~mm}$.

The target function is defined by the minimization of cogging torque divided by maximum cogging torque $T_{c \max }$ at any rotor position $\theta$, expressed in Eq. (3):

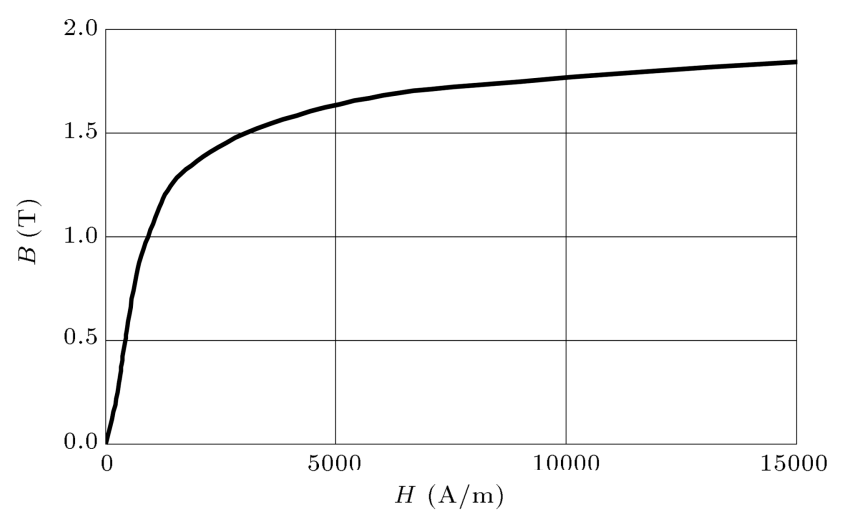

Figure 1. Magnetic core characteristic of the proposed IPMSM.

$$
\begin{aligned}
O F & =\min \left(\frac{T_{c}}{T_{c \max }}\right) \\
& =\min \left(\frac{l \pi}{4 \mu_{0} T_{c \max }} \times\left(R_{1}^{2}-R_{2}^{2}\right)\right. \\
& \left.\sum_{n=0}^{\infty} n N_{c} B_{a n} \sin \left(n N_{c} \theta\right)\right) .
\end{aligned}
$$

Optimization process using genetic algorithm is carried out by optimization toolbox of MATLAB software. The output results using analytical approach before (Design 1) and after the optimization by GA (Design 2) are listed in Table 1. $T_{c \text { rms }}$ is RMS value of cogging torque.

Peak-peak and RMS values of cogging torque are the main parameters of torque ripple reduction. Peakpeak cogging torque is twice the peak value of cogging torque. Therefore, according to Table 1, optimization of rotor structure by GA (design 2) has slight success in relation to the initial design. The cogging torque of Design 2 is reduced only $4.5 \%$ related to Design 1. Therefore, in the following sections, the cogging torque will decrease even more using combination of two ideas, i.e. segmented PM and flux barrier optimization.

\subsection{Segmented PM}

There are several articles in the field of IPMSM optimization based on segmented PM [6-7]. Segmented PM is a well-known IPMSM optimization technique that creates iron bridges between PMs, which are always in saturation. These iron bridges have two advantages:

1. Flux linkage of neighboring PMs decreased due to the flux crossing through these paths;

2. $L_{d}$ increased because iron bridges are placed through $d$ axis of the motor.

According to Figure 2, the relation between pole arcs and number of segmented PM can be described by

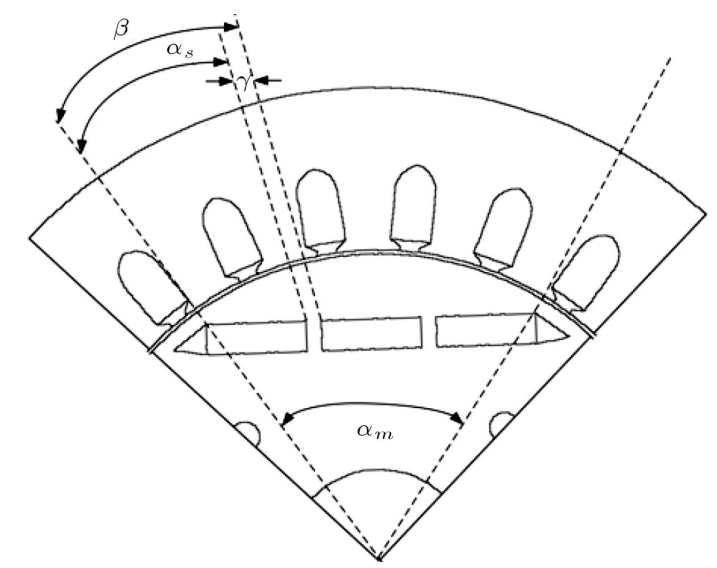

Figure 2. PM and flux barrier configuration. 
Table 1. Motor parameter before/after optimization.

\begin{tabular}{|c|c|c|c|c|c|c|c|c|c|}
\hline & $\begin{array}{c}\text { Air } \\
\text { gap } \\
(\mathrm{mm})\end{array}$ & $\begin{array}{c}\text { Rotor } \\
\text { diameter } \\
(\mathbf{m m})\end{array}$ & $\begin{array}{c}\text { PM } \\
\text { length } \\
(\mathrm{mm})\end{array}$ & $\begin{array}{c}\text { PM } \\
\text { width } \\
(\mathrm{mm})\end{array}$ & $\begin{array}{c}\text { PM } \\
\text { thickness } \\
(\mathrm{mm})\end{array}$ & $\begin{array}{c}L_{d} \\
(\mathbf{m H})\end{array}$ & $\begin{array}{c}L_{q} \\
(\mathrm{mH})\end{array}$ & $\begin{array}{c}T_{c \max } \\
(\mathbf{N} \cdot \mathbf{m} / \mathbf{m})\end{array}$ & $\begin{array}{c}T_{c r m s} \\
(\mathrm{~N} . \mathrm{m} / \mathrm{m})\end{array}$ \\
\hline Design 1 & 0.8 & 155.5 & 111 & 96.8 & 8.5 & 1.2 & 8 & 0.8 & 0.44 \\
\hline Design 2 & 1 & 155.1 & 111 & 87 & 9 & 0.8 & 6.4 & 0.74 & 0.42 \\
\hline
\end{tabular}

Eq. (4) as follows:

$$
\alpha_{m}=s \alpha_{s}+(s-1) \gamma
$$

where $s, \alpha_{s}, \gamma$, and $\alpha_{m}$ are the number of segmented PMs, PM arc length, arc length between segmented $\mathrm{PMs}$, and a pole arc, respectively. The Fourier coefficient of air-gap magnetic flux density $B_{a n}$ is expressed in Eq. (5) [6]:

$$
B_{a n}=\frac{B_{g}}{\pi n N_{c} / p} \sin \left(n N_{c} \alpha_{s} / 2\right) \times \sum_{i=0}^{s-1} \cos \left(i n N_{c} \beta\right) \text {. }
$$

For eliminating the cogging torque, Eq. (5) must be set to zero as expressed in Eq. (6):

$$
n N_{c} \alpha_{s} / 2=k \pi, \quad \text { or } \quad \sum_{i=0}^{s-1} \cos \left(i n N_{c} \beta\right)=0 .
$$

The empirical formula for obtaining the optimized number of segmented PM is expressed in Eq. (7) [9]:

$$
n=\frac{k \varphi_{\max }}{\gamma l_{m} B_{s a t} N_{c} k_{w}}+1,
$$

where $k_{w}, \varphi_{\max }, B_{s a t}, k$, and $l_{m}$ are winding factor, maximum flux density of each pole, saturated flux density of iron bridge, flux linkage of PM divided by iron bridge, and PM length, respectively. By solving Eq. 6, the optimal values of $\alpha_{s}$ and $\gamma$ are obtained. Based on motor specification (in the appendix) without segmented PM and above information, Design 2 is obtained as the first optimization motor. If we incorporate PM segmentation into the optimization process using Eq. (7), four segmented PMs with 1.5 $\mathrm{mm}$ iron bridge will carry out the second optimized motor as in Design 3. The configuration and magnetic flux density distribution of Design 3 and cogging torque waveform of two optimized designs (Designs 2 and 3) are illustrated in Figures 3 and 4, respectively.

The peak-peak and RMS values of the cogging torque of Design 3 related to Design 2 are reduced by $27 \%$ and $13 \%$, respectively. Table 2 shows the performance analysis of two optimized Designs. $T_{e}$ and $T_{r}$ are electromagnetic and reluctance torque components of output torque, respectively. $T H D_{-} B_{g}$ is total harmonic distortion of air-gap magnetic flux density.

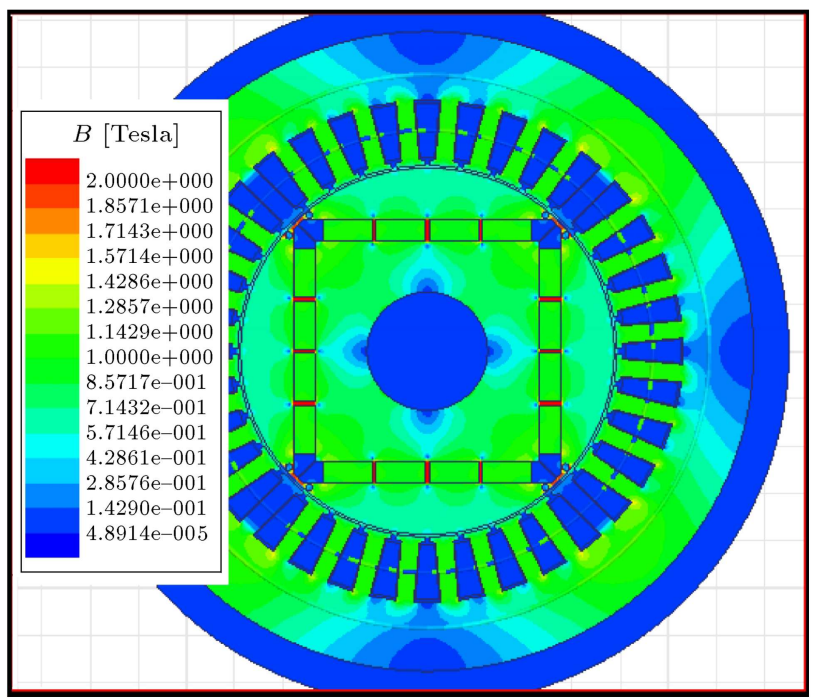

Figure 3. Magnetic flux density distribution of design 3.

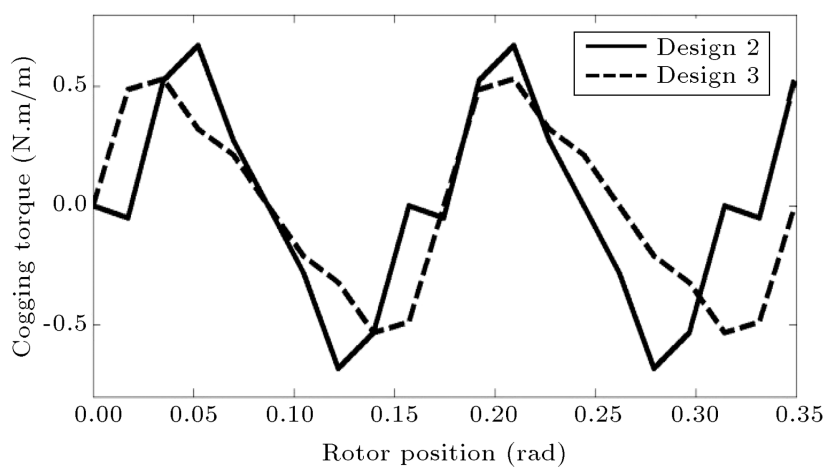

Figure 4. Cogging torque of Designs 2 and 3.

According to Table 2, the motor magnetizing flux $(\Psi \mathrm{m})$ and difference between inductances $\left(L_{q^{-}}\right.$ $L_{d}$ ) of Design 3 are decreased; therefore, the output power of Design $3\left(P_{n}\right)$ reduced too (almost $8 \%$ ). However, the THD of air-gap magnetic flux density of Design 3 decreased in comparison with Design 2, which is favorable. For more reduction of cogging torque, redesigning IPMSM will be done based on putting flux barrier in the rotor structure in the next section.

\subsection{Redesigning IPMSM using configuration of the optimized flux barrier}

Suitable flux barrier configuration has great effect on cogging torque reduction. The flux barrier transfers 
Table 2. Comparison of Designs 2 and 3

\begin{tabular}{lcccccccc}
\hline & $\begin{array}{c}\boldsymbol{L}_{\boldsymbol{d}} \\
(\mathbf{m H})\end{array}$ & $\begin{array}{c}\boldsymbol{L}_{\boldsymbol{q}} \\
(\mathbf{m H})\end{array}$ & $\begin{array}{c}\boldsymbol{L}_{\boldsymbol{q}}-\boldsymbol{L}_{\boldsymbol{d}} \\
(\mathbf{m H})\end{array}$ & $\boldsymbol{\Psi}_{\boldsymbol{m}}(\mathbf{m W e b})$ & $\boldsymbol{T}_{\boldsymbol{r}}(\mathbf{N} \cdot \mathbf{m} / \mathbf{m})$ & $\boldsymbol{T}_{\boldsymbol{e}}(\mathbf{N} . \mathbf{m} / \mathbf{m})$ & $\boldsymbol{P}_{\boldsymbol{n}}(\mathbf{K W})$ & $\mathbf{T H D} \boldsymbol{B}_{\boldsymbol{g}}(\boldsymbol{\%})$ \\
\hline Design 2 & 0.98 & 6.1 & 5.12 & 580 & 12.8 & 40.3 & 8.8 & 23 \\
Design 3 & 1.2 & 4.9 & 4.9 & 522 & 15.2 & 36.3 & 8.1 & 19 \\
\hline
\end{tabular}

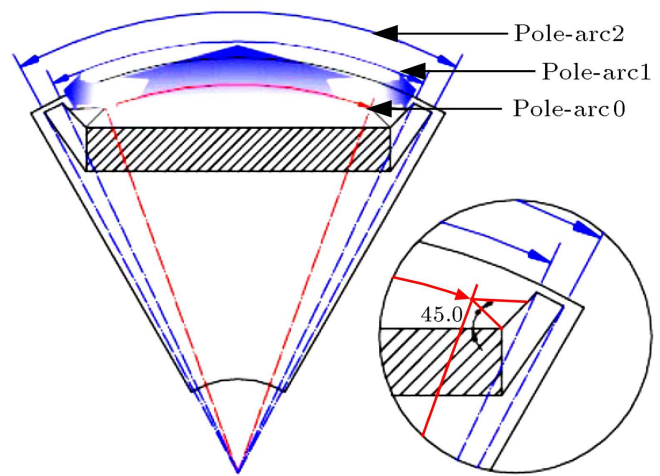

Figure 5. Flux barrier configuration used in Design 4.



Figure 6. Output results of RSM for Design 4.

the PM flux into the air gap, and then the air gap magnetic flux density will increase. For obtaining the optimal placement of flux barriers in the rotor body, three parameters of flux barrier (pole-arc 0, pole-arc 1 , and pole-arc 2) must be well calculated to obtain the minimum cogging torque. Figure 5 illustrates the typical flux barriers and pole-arc positions in the rotor body.

We have three degrees of freedom for modifying the rotor flux barrier. In order to find the suitable position of flux barrier into rotor body, some limitations must be considered listed in Table 3 . Using magneto static FEM analysis and Response Surface Method (RSM) as optimization technique, optimal position of flux barrier in the rotor body is obtained. The output power is held constant during optimization process by air-gap magnetic flux density $B_{g}$ limitation, depicted in Table 3. Figure 6 shows 3D output of RSM results for minimizing the cogging torque (R1). The minimum
Table 3. limitation of optimization for Design 4

\begin{tabular}{lcccc}
\hline & $\begin{array}{c}\text { Pole-arc0 } \\
\text { (degree) }\end{array}$ & $\begin{array}{c}\text { Pole-arc1 } \\
\text { (degree) }\end{array}$ & $\begin{array}{c}\text { Pole-arc2 } \\
\text { (degree) }\end{array}$ & $\boldsymbol{B}_{\boldsymbol{g}}(\mathrm{T})$ \\
\hline Interval & $63-68$ & $81-84$ & $88-89$ & $0.68-0.72$ \\
\hline
\end{tabular}

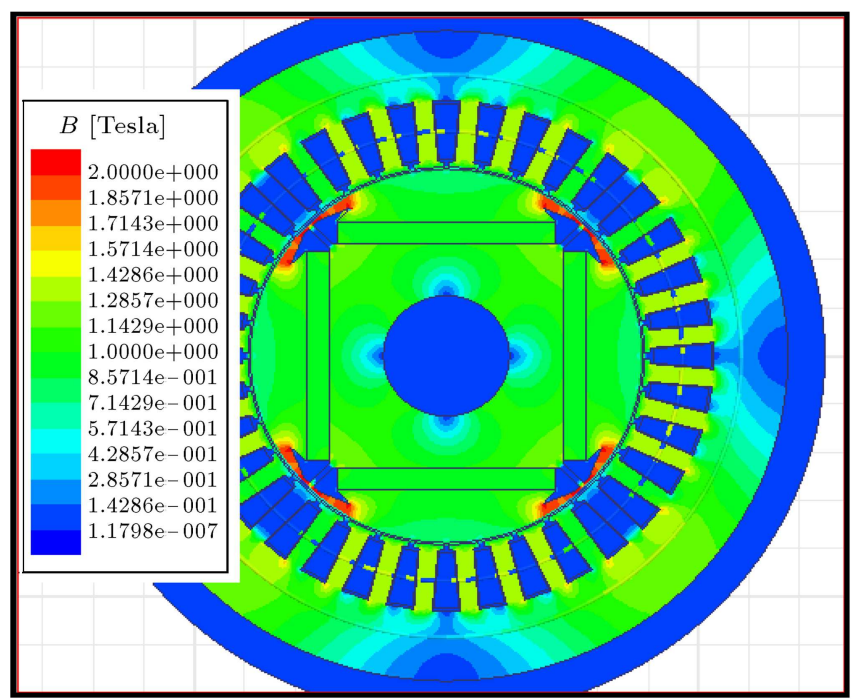

Figure 7. Magnetic flux density distribution of Design 4.

point is obtained by pole-arc $0=64.02$ degree, pole-arc $1=83.38$ degree, pole-arc $2=88.24$ degree with the minimum cogging torque value of $0.47 \mathrm{~N} . \mathrm{m} / \mathrm{m}$. This design is called Design 4. Magnetic flux density distribution of Design 4 is illustrated in Figure 7 . The output parameters of Design 4 are listed in Table 4.

This optimization design in comparison with Designs 2 and 3 has some advantages:

- The air-gap flux density is more sinusoidal due to the lowest THD of $B_{g}$;

- The cogging torque decreases more in relation to other designs $\left(T_{\text {crms }}=0.27 \mathrm{~N} . \mathrm{m} / \mathrm{m}\right)$.

However, in this design, the output power increased due to the increase of reluctance torque component $T_{r}$ and low increase of electromagnetic torque $T_{e}$. Increasing the reluctance torque creates a torque ripple in addition to the cogging torque in the output torque. In this paper, an optimized design is proposed by the combination of flux barrier configuration with segmented PM. 
Table 4. Comparison of Designs 2 and 4 .

\begin{tabular}{cccccccccc}
\hline & $\begin{array}{c}\boldsymbol{L}_{\boldsymbol{d}} \\
(\mathbf{m H})\end{array}$ & $\begin{array}{c}\boldsymbol{L}_{\boldsymbol{q}} \\
(\mathbf{m H})\end{array}$ & $\boldsymbol{L}_{\boldsymbol{q}}$ & $\begin{array}{c}\mathbf{\Psi} \mathbf{m} \\
(\mathbf{m W e b})\end{array}$ & $\begin{array}{c}\boldsymbol{T}_{\boldsymbol{r}} \\
(\mathbf{N . m} / \mathbf{m})\end{array}$ & $\begin{array}{c}\boldsymbol{T}_{\boldsymbol{e}} \\
(\mathbf{N} . \mathbf{m} / \mathbf{m})\end{array}$ & $\begin{array}{c}\boldsymbol{P}_{\boldsymbol{n}} \\
(\mathbf{k W})\end{array}$ & $\begin{array}{c}\boldsymbol{T}_{\mathbf{c r m s}} \\
(\mathbf{N} . \mathbf{m} / \mathbf{m})\end{array}$ & $(\mathbf{T H D}) \boldsymbol{B}_{\boldsymbol{e}}(\boldsymbol{\%})$ \\
\hline Design 2 & 0.98 & 6.1 & 5.12 & 580 & 12.8 & 40.3 & 8.8 & 0.44 & 23 \\
Design 4 & 0.95 & 7.4 & 6.45 & 622 & 20 & 43.3 & 9.9 & 0.27 & 14 \\
\hline
\end{tabular}

Table 5. Comparison of all designs.

\begin{tabular}{|c|c|c|c|c|c|c|c|c|}
\hline & $\begin{array}{c}L_{d} \\
(\mathbf{m H})\end{array}$ & $\begin{array}{c}L_{q} \\
(\mathbf{m H})\end{array}$ & $\begin{array}{c}\Psi \mathbf{m} \\
(\mathrm{mWeb})\end{array}$ & $\begin{array}{c}T_{r} \\
(\mathrm{~N} . \mathrm{m} / \mathbf{m})\end{array}$ & $\begin{array}{c}T_{e} \\
(\mathrm{~N} . \mathrm{m} / \mathbf{m})\end{array}$ & $\begin{array}{c}P_{n} \\
(\mathrm{~kW})\end{array}$ & $(\mathrm{THD}) \boldsymbol{B}_{g}(\%)$ & $\begin{array}{c}T_{\text {crms }} \\
(\mathrm{N} . \mathrm{m} / \mathrm{m})\end{array}$ \\
\hline Design 2 & 0.98 & 6.1 & 580 & 12.8 & 40.3 & 8.8 & 23 & 0.42 \\
\hline Design 3 & 1.2 & 4.9 & 522 & 15.2 & 36.3 & 8.1 & 19 & 0.34 \\
\hline Design 4 & 0.95 & 7.4 & 622 & 20 & 43.3 & 9.9 & 14 & 0.27 \\
\hline Proposed design & 1.3 & 7.5 & 521 & 19.2 & 36.3 & 8.7 & 10 & 0.24 \\
\hline
\end{tabular}

\section{The proposed design}

Using segmented PM, the THD of air-gap magnetic flux density and reluctance torque component will decrease. By employing RSM for optimum position and configuration of flux barrier, the torque ripple will decrease. In other words, optimization of flux barrier configuration leads to the increase of $L_{d}$ and decrease of $L_{q}-L_{d}$, affecting the reduction of reluctance torque without decreasing the output torque. Flowchart of the proposed design is illustrated in Figure 8. At first, the initial design (which can be Design 2) is defined.

The configuration of flux barrier is obtained using RSM; then, the initial value of arc between PMs, ' $\gamma$ ' for selecting the suitable number of segmented PMs is calculated. If air-gap magnetic flux density $0.68 T \leq B_{g} \leq 0.72 T$, then this design will be optimized; otherwise, the value of $\gamma$ is increased by one and the inner loop of flowchart will be repeated till the magnetic flux density is in range. Finally, the proposed design's performance, called Design 5, is compared with those of other designs in Table 5 . The number of segmented PMs is 4 with $1.4 \mathrm{~mm}$ iron bridge in width. The peak value of magnetic flux density in the air gap is $0.72 T$. Magnetic flux density and magnetic flux lines of the proposed design are shown in Figure 9(a) and $9(\mathrm{~b})$, respectively.

According to Table 5, the proposed design has the lowest value of air-gap flux density THD, i.e. $10 \%$. The output power of the proposed design is very close to the pre-defined value $(9 \mathrm{~kW})$ and value of $L_{q}-L_{d}$ decreases related to Design 4; therefore, the reluctance torque is reduced related to the Design 4 . The cogging torque of the proposed design is decreased by $62 \%$, i.e. $0.24 \mathrm{~N} . \mathrm{m} / \mathrm{m}$ in comparison with Design 2 .

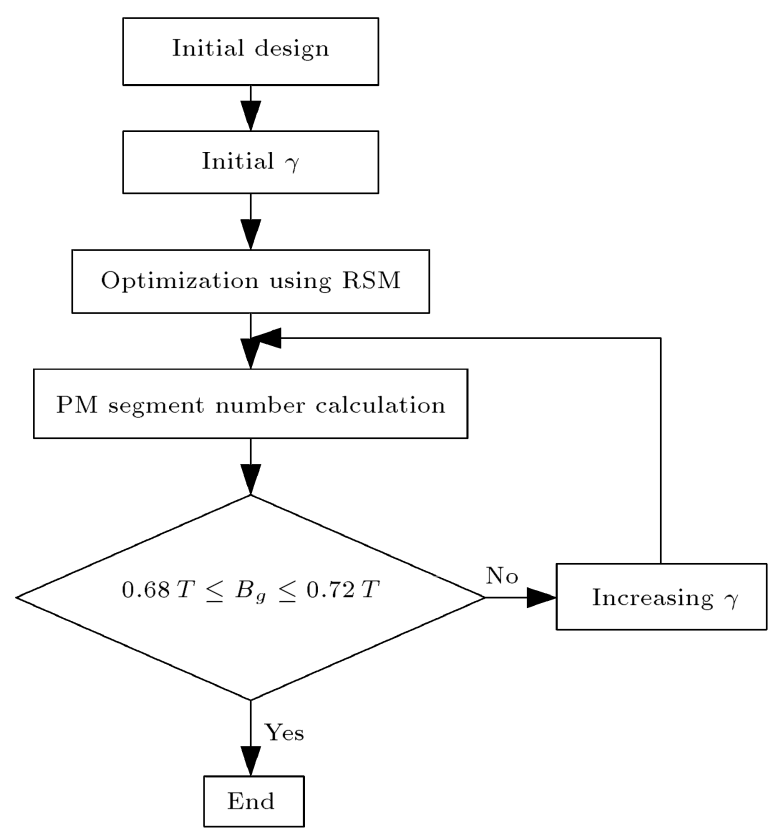

Figure 8. Flowchart of the proposed design.

\section{Conclusion}

In this paper, using combination of two separate ideas, i.e. segmented PM in rotor body and optimized design of suitable flux barriers, an optimized design of IPMSM based on cogging torque reduction is proposed. Optimization process is carried out by Response Surface Method (RSM). In the proposed design, called Design 5, the cogging torque is decreased by $62 \%$ related to the usual design (Design 2); in addition, $L_{q}-L_{d}$ values of that are reduced, too. The THD value of the air-gap magnetic flux density of the proposed design has the lowest value related to the other designs which is equal to $10 \%$. 


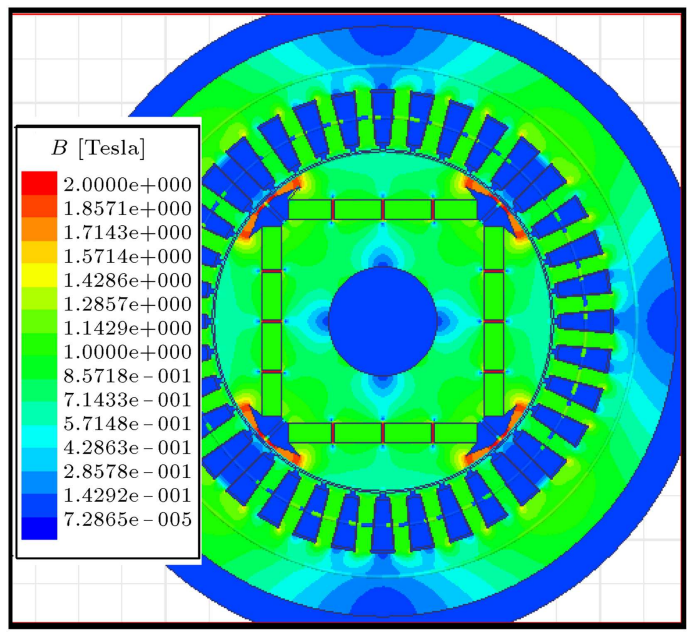

(a)

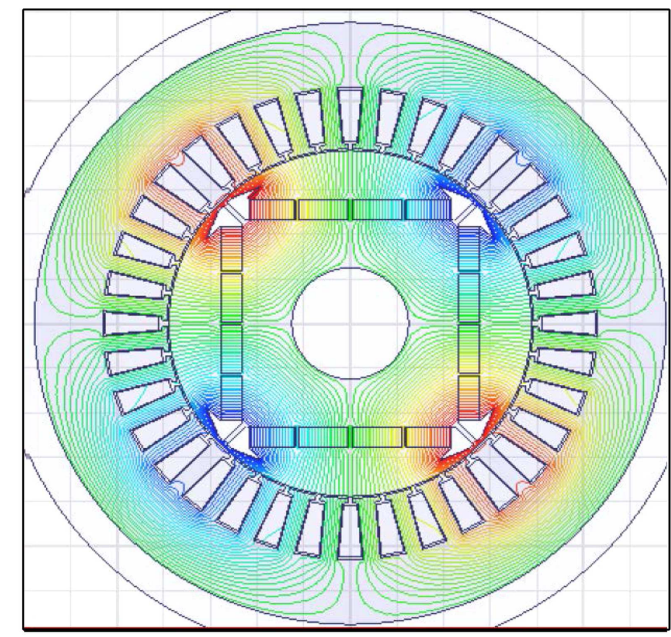

(b)

Figure 9. The proposed design: (a) Magnetic flux density distribution, and (b) magnetic flux lines.

\section{References}

1. Dutta, R. and Rahman, M.F. "Design and analysis of an interior permanent magnet (IPM) machine with very wide constant power operation range", IEEE Transactions on Energy Conversion, 23(1), pp. 25-33 (2008).

2. Fang, L. and Hong, J.P. "Flux-barrier design technique for improving torque performance of interior permanent magnet synchronous motor for driving compressor in HEV," Conference in Vehicle Power and Propulsion, pp. 1486-1490 (2009).

3. Kim, D.H., Park, H., Lee, J.H., and Kim, C.E. "Optimal shape design of iron core to reduce cogging torque of IPM motor", IEEE Transactions on Magnetics, 39(3), pp. 1456-1459 (2003).

4. Kang, G.H., Son, Y.D., Kim, G.T., and Hur, J. "A novel cogging torque reduction method for interiortype permanent-magnet motor ", IEEE Transactions on Industry Applications, 45(1), pp. 161-167 (2009).

5. Park, J.U., Cho, J.H., Chung, D.H., So, J.Y., and Kim, D.K. "A rotor shape design of interior PM motor for reducing cogging torque in electric air-conditioning system of HEV", International Conference on Electrical Machines and Systems (ICEMS), pp. 1139-1143 (2013).

6. Dutta, R., Sayeef, S., and Rahman, M.F. "Cogging torque analysis of a segmented interior permanent magnet machine", Electric Machines \& Drives Conference, IEMDC07, pp. 781-786 (2007).

7. Lee, S.T. "Development and analysis of interior permanent magnet synchronous motor with field excitation structure," PhD Thesis, University of Tennessee (2009).

8. Arehpanahi, M. and Sanaei, V. "Optimal design of interior permanent magnet motor $\mathrm{f}$ with wide flux weakening range," Scientia Iranica D, 22(3), pp. 1045$1051(2015)$
9. Dutta, R. "A Segmented Interior Permanent. Magnet Synchronous Machine with wide field-weakening range" PHD Thesis, The University of New South Wales (2007).

\section{Appendix}

The detailed parameters of typical IPMSM for optimization are listed in Table A.1.

Table A.1. IPMSM parameters.

\begin{tabular}{ccc}
\hline Symbol & Quantity & Values \\
\hline$D y$ & Outer stator diameter & $270.7 \mathrm{~mm}$ \\
$D_{s}$ & Inner stator diameter & $157.1 \mathrm{~mm}$ \\
$Q s$ & Number of stator slots & 36 \\
$l_{f e}$ & Active machine length & $111 \mathrm{~mm}$ \\
$A_{s l o t}$ & Stator slot area & $247.1 \mathrm{~mm}^{2}$ \\
$b t s$ & Stator tooth width & $6 \mathrm{~mm}$ \\
$b o$ & Slot opening & $2 \mathrm{~mm}$ \\
$g$ & Air-gap length & $0.8 \mathrm{~mm}$ \\
$D_{s h}$ & Shaft diameter & $50 \mathrm{~mm}$ \\
$D_{r}$ & Rotor core diameter & $155.5 \mathrm{~mm}$ \\
$V_{m}$ & Magnet volume & $365397 \mathrm{~mm}$ \\
$W_{m}$ & Magnet thickness & $8.5 \mathrm{~mm}$ \\
$L_{m}$ & Magnet width & $96.8 \mathrm{~mm}$ \\
$\mu_{r}$ & PM relative permeability & 1.099781 \\
$H_{c}$ & PM coercive force & $890 \mathrm{kA} / \mathrm{m}$ \\
$B_{r}$ & PM residual flux density & $1.22 \mathrm{~T}$ \\
\hline
\end{tabular}




\section{Biographies}

Mehdi Arehpanahi was born in Kermanshah, Iran, in 1978. He received a BS degree from Tabriz University in 2000, and MS and $\mathrm{PhD}$ degrees from Amirkabir University of Technology, Tehran, Iran in 2003 and 2009, respectively. He is currently an Assistant Professor in the Electrical Engineering Department of Tafresh University, Iran. His research interests include work on computational electromagnetics, electrical machine design and drives.

Hamed Kashefi was born in Bousher, Iran in 1987. He obtained a BS degree from Persian Gulf University Iran, in 2010 and an MS degree in Electrical Engineering (Power Systems) from Tafresh University, Iran, in 2014. He is currently teaching in the Islamic Azad University of Bushehr, Iran. 